\title{
The relationship between Emotional Divorce and Motivation for Achievement among Working Women
}

\section{Doaa Gad Assr (Ph.D)}

Assistant professor social work with individuals and families Institute of Social Work, Banha

\section{Shimaa Mahmoud Abd-elmaksoud (Ph.D)}

Assistant professor social work with individuals and families

Faculty of Social Work Helwan university 


\section{Abstract}

This study aims to determine the relationship between emotional divorce and achievement motivation for working women. It aims to identify the indicators of the role of social workers in dealing with emotional divorce and achievement motivation for working women. We selected a targeted sample of (100) working women.

The study concluded that there is an inverse correlation relationship with statistical significance between emotional divorce in its various dimensions (physical, psychological, social, emotional, and professional) and achievement motivation for working women at a significance level (0.01). There is a direct, statistically significant relationship between the variables of age and family income for the working woman and her emotional divorce at a significance level (0.01) There is no statistical indication of the educational status of the working woman, the educational status of the husband, the employment status of the working woman.

Key words:(Emotional divorce - Achievement motivation - working woman)

\section{Introduction}

The emotional divorce between the spouses is called false social harmony, as the relationship between the partners seems to have prevailed in permanent peace, keeping respect for ach other. However, it is in fact unbearable for the spouses, and this is what happens in developing countries such as Arab societies, where it is difficult to isolate the family from society (Khoury, 2008).

Statistics of marriage in Egypt indicate a continuous increase in all governorates. In 2014 , it reached $(909,350)$ marriage contracts, while in 2019 it reached (927840) marriage contracts. On the other hand, the rate of divorce in 2014 increased to (2.6) per thousand of the population. Then in 2018 it had a ratio of (2.9) per thousand of the population, and the highest divorce rate is in the age group. (Central Agency for Mobilization and Statistics, 2019).

The results of Afrasiabi. \& Jafarizadeh, (2015) research show that individual factors are not equally effective on an emotional divorce. There is a significant relationship between emotional divorce and these factors: sex, understanding of spouse, using nice words by spouse, spouse expectations, understanding spouse situations and using drugs. However, there is not any significant relation between emotional divorce and these factors: doubt and pessimism, misplaced 
expectations, occupational differences, age, educational differences, forced marriage.

Emotional divorce is increasing more rapidly in developing countries, where technological and communication developments have revealed the 'new' western marital culture of egalitarian and individualist values to people in third-world communities where traditional and patriarchal cultures are the norm. (Barzoki, et.al., 2015, P. 108). Children of emotionally divorced parents showed significantly higher levels of emotional and behavioral problems than counterparts from legally divorced parents. They reported more depression, anxiety, stress, and aggression. Additionally, moderate, severe, and extremely severe levels of emotional and behavioral problems were more common among emotional divorce children than legal divorce ones (Hashemi \& Homayuni, 2017).

Many wives who suffer from emotional divorce are women who work in various fieldsAs women resort to work to help themselves, their children or their husbands, and this work may be considered a cause of threatening family cohesion., Among the factors that push women out to work are economic, social, cultural and personal factors, represented in proving themselves and relying on herselves(Hamza, et al., 2016, p. 30-32)

The achievement motivation are regards behavior as a function of the three components: motives, probability of success, and incentive value. All of these components describe personal characteristics. Hence, people come to different performance choices not because the mechanism of choosing is different, but because of individual differences in motives, perceived probability of success, and incentive value. (Tempelaar, et al., 2011.p. 397)

\section{Second: The objectives of the study:}

This study aims mainly and directly to study the relationship between emotional divorce and achievement motivation for working women, through:

1- Determining the level of emotional divorce of the working woman. 2- Determining the level of achievement motivation for working women.

3- Determine the nature of the relationship between emotional divorce and achievement motivation for working women. 


\section{Third: Hypotheses of the study:}

1. There is an inverse correlation relationship of statistical significance between emotional divorce and achievement motivation of the working woman "study sample".

2. There is a statistically significant correlation between some demographic variables (age, educational status of the working woman, the educational status of the husband, the employment status of the working woman, family income) and the emotional divorce of the working woman "study sample".

3. There is a statistically significant correlation between some demographic variables (age, the educational status of the working woman, the educational status of the husband, the employment status of the working woman, the family income) and the achievement motivation of Working woman "study sample."

\section{Fourth: Study Concepts:}

\section{1-Emotional Divorce:}

It is known as the abandonment of the husband to his wife, whether he abandoned the emotional relationship, or abandoned the conversation and lost affection and housing, so that people showed the integrity of the marital relationship and reality unlike it. (AlHaqbani, 2013, p. 14). The definition of emotional divorce theoretically in this study is familial turmoil, with the spouses continuing to live together under one roof in the form of bad relationships and lack of communication and interaction between them.

The procedural definition of emotional divorce: It is the sum of the scores that a working woman obtains in each of the social, economic, psychological, emotional and professional aspects in the emotional divorce scale.

\section{2-Achievement Motivation}

It is the desire of the individual and his tendency to accomplish the tasks, tasks and duties entrusted to the mechanism of the best possible level and the highest possible point, so that he attains the satisfaction of his superiors and opens up ways for him to increase income, and facilitate the flow of mercenaries and progress towards what some employees and dealers have (Taha, et al., 2003, p. 352).

The theoretical definition of achievement motivation: It is the ability of the working woman to perform her jobs and duties and achieve her goals within the family and workplace, and to overcome the difficulties she faces. 
The procedural definition of achievement motivation: It is the sum of the scores that the working woman obtains in her ability to get success and to get appreciation, satisfaction with work, Perseverance and Stamina and avoid failure in the achievement motivation scale.

The theoretical guidelines for the study:

Role theory:

Social role theory's focus on the factors that interact with the definition and redefinition of gender roles fits nicely with the family life cycle model. For example, one of the major life cycle transitions occurs when moving from being a young couple to being a couple with children. This transition requires the addition of new mother and father roles and a redefinition of the partner roles. These periods of transition often create stress or strain on the couple or family as they renegotiate roles and role assignments. (Stanton\& Lee. 2017, p.5)

1-The Role Conflict :Work/family conflict is an important concept in the analysis of the interface between work and family (Voydanoff, 1988, p.749). Work-family role conflict has been identified as one of the factors that inhibit women from actively participating in paid work, especially for women in science and technology. As long as the modern day family structure continues to be the dual-earner type, issues concerning the incompatibility of work demands and family demands will continue to arise (Uzoigwe, et al., 2016, p. 629)

2-Total role: Bruch and Barnett (1986) focused on the quality and nature of multiple roles, especially the quality of women's roles as wives, mothers and paid employees. (Chang, \& Kim, 2016, p. 529).

3-Changing Roles: Roles change in a woman's life according to the age and career changes she is going through. Whenever changes happen to the wife or husband, the roles increase and he may leave some roles within the family to account for other roles at work. (AlSiddiqi et al., 2004, p. 76)

4-Role Dissonance: The planner offers plans which express how he wishes the client would behave or might be capable of behaving, without really considering the clients realistic capacities or his state of readiness to accept new patterns of behavior.( Mayo, et al., 2011, 98).

\section{Fifth: the study's methodological procedures:}

Type of study: This study belongs to the style of comparative descriptive studies to determine the relationship between two variables, namely, emotional divorce and achievement motivation. 
Study methodology: The researcher relied on the social survey method by the intentional sampling method. This is in order to obtain a set of data and interpret them in terms of their subject matter to clarify the relationship between the study variables.

Study Population: The number of women working in the Integrated Women's Services Complex in Banha, Qalyubia Governorate, is about (421) working women.

- The type and size of the sample: An intentional sample was drawn from the members of the Integrated Women's Services Complex in Banha, Qalyubia Governorate, where the total sample size was (100) working women, and it was determined according to the following Sample terms: 1 -To be one of the wavering members or (subscribers) of the Women's Services Complex integrated into her.

2-The continuation of the spouses in one house despite their emotional divorce

3-The commitment of spouses not to leave the house and not to go to the courts.

4-More than two years have passed since the formation of the family (marriage).

5-The children in the family are the legal children of both spouses and are not children of either spouse.

C- The sampling unit: the working woman, the sample of the aforementioned study.

Study tools: The two researchers relied on two measures to collect data, and study and analyze the subject of the study:

\section{A-The measure of emotional divorce.}

\section{B-The measure of achievement motivation.}

The following is an explanation of the structure of the tools that were used in the study:

A- The emotional divorce scale: The two researchers, when designing the scale, looked at previous studies and research, and theoretical writings that focused on emotional divorce and its dimensions, and the scale was designed as follows:

The first part: includes personal data related to (age, educational status of the working woman, the educational status of the husband, your arrangement between marriages, years of emotional divorce, the employment status of the working woman, number of children, family income, precedent marriage, number of previous marriages, number of children Previous marriage) and making the name 
optional, the instructions regarding the manner of response and what the respondents take into account in their response.

Part Two: It includes (45) phrases distributed on five dimensions: (physical, psychological, social, emotional, and professional). The method of response has been determined; where the responses were (yes-sometimes-no) and the response was made on the same phrase sheet to not be distracted or error-prone.

In designing the scale, the two researchers took into account the following:

A- Determine the type of data to be obtained.

B- Putting expressions that are closely related to the aim of the study.

C- Ease of expressions and clarity of their content, with verification when testing the scale.

D- The statements correspond to the educational and cultural level of the study sample.

The validity and consistency of the emotional divorce scale in the current study:

A- Honesty: The two researchers have relied on two types of honesty, namely:

1. The validity of arbitrators: The measure of emotional divorce was presented to a number of professors of sociology, social service, psychology, and field practice, provided that arbitration takes place in the light of: 1 . The extent to which the phrase is related to each axis of the study. 2. In terms of phrasing of the phrase.

3. In terms of content. Accordingly, the general dimensions of the scale have been modified, and some expressions have been amended, and expressions on which the percentage of agreement is less than $85 \%$ have been deleted, and the percentage of agreement was calculated according to the (Getman) formula.

2. Validity of internal consistency: The two researchers calculated the internal consistency of the scale paragraphs on a sample of (20) single size, in order to calculate the correlation coefficients between each paragraph and the total degree of its field, and we will deal with each area separately, as shown in the following tables: 
Table (1) illustrates Correlation coefficients between degree of statements and degree of dimension to which they belong

\begin{tabular}{|c|c|c|c|c|c|c|c|c|c|}
\hline 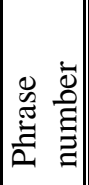 & 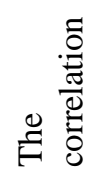 & 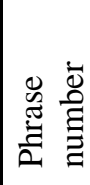 & 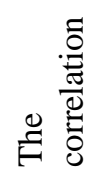 & 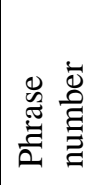 & 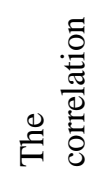 & 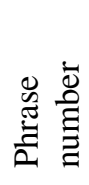 & D. & 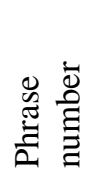 & 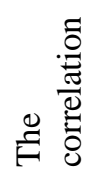 \\
\hline$\overline{1}$ & 0.589 & 2 & 0.811 & 3 & 0.632 & 4 & 0.502 & 5 & 0.625 \\
\hline 6 & 0.783 & 7 & 0.829 & 8 & 0.611 & 9 & 0.670 & 10 & 0.778 \\
\hline 11 & 0.589 & 12 & 0.487 & 13 & 0.518 & 14 & 0.814 & 15 & 0.625 \\
\hline 16 & 0.492 & 17 & 0.478 & 18 & 0.558 & 19 & 0.670 & 20 & 0.661 \\
\hline 21 & 0.502 & 22 & $\overline{c 0.804}$ & 23 & 0.518 & 24 & 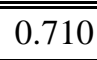 & 25 & 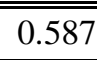 \\
\hline 26 & 0.782 & 27 & 0.478 & 28 & 0.471 & 29 & 0.810 & 30 & 0.510 \\
\hline 31 & 0.652 & 32 & 0.601 & 33 & 0.804 & 34 & 0.777 & 35 & 0.782 \\
\hline 36 & 0.622 & 37 & 0.710 & 38 & 0.661 & 39 & 0.814 & 40 & 0.670 \\
\hline 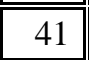 & 0.739 & $\overline{424}$ & 0.770 & $\begin{array}{l}43 \\
\end{array}$ & 0.778 & 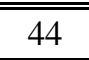 & 0.558 & 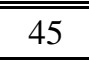 & 0.601 \\
\hline
\end{tabular}

The tabular value is at the level of significance (0.05) and the degree of freedom (18), which equals (0.444). It is evident from the previous table on the correlation coefficients between each paragraph of the axes of emotional divorce and the total degree of its paragraphs that the correlation coefficients range between $(0.471-0.829)$; and it is considered a function at the level of significance (0.01). This gives an indication of the high coefficients of internal consistency, as it indicates to high and sufficient validity indicators that can be trusted in the application of the current study.

Table (2) illustrates It shows the correlation coefficients between dimension score and overall score for the emotional divorce scale

\begin{tabular}{|c|c|c|c|}
\hline $\mathrm{Sr}$ & Patterns & Correlation coefficient & "Significance level \\
\hline 1 & The physical aspect & $0.611^{* *}$ & 0.01 \\
\hline 2 & The psychological aspect & $0.771^{* *}$ & 0.01 \\
\hline 3 & Social side & $0.810^{* * *}$ & $\overline{0.01}$ \\
\hline "4 & $\overline{\text { Affective side }}$ & (0.589** & 0.01 \\
\hline$\overline{\overline{5}}$ & The professional side & 年.618** & $\overline{0.01}$ \\
\hline
\end{tabular}

** significant at 0.01

* significant at 0.05

It is evident from the previous table that the aspects of emotional divorce among working women have a statistical significance at the level of (0.01). This gives an indication of the high internal consistency coefficients, and it indicates high and sufficient 
validity indicators that can be trusted in the application of the current study.

B- Reliability: The researchers used two methods to ensure the stability of the scale, namely:

1. Re-applying the scale: The two researchers calculated the scale stability factor, using the Test-Retest method, where they applied the scale to a sample to determine the psychometric properties. Then they were re-applied to the same sample after an interval of (15) days. That is, two weeks later, the two researchers calculated the correlation coefficients between the scores of the cases in the first and second applications using the Pearson correlation coefficient, and its amount was (0.776). This is a high-value coefficient that is significant at a level of significance (0.01), which indicates that the measure of emotional divorce among women working on High degree of stability.

2. The Cronbach Alpha Method: The two researchers measured the reliability of the emotional divorce scale for working women, using the Cronbach alpha reliability coefficient, and the following table shows the reliability coefficient of the scale dimensions, namely:

Table (3) illustrates Cronbach's alpha reliability coefficient for the dimensions of the emotional divorce scale of the working woman

\begin{tabular}{||c||l||l||}
\hline \hline Sr. & The dimension & Stability coefficient \\
\hline \hline 1 & physical aspect & $0.821^{* *}$ \\
\hline \hline 2 & Psychological aspect & $0.736^{* *}$ \\
\hline \hline 3 & Social aspect & $0.611^{* *}$ \\
\hline \hline 4 & Affective & $0.657^{* *}$ \\
\hline \hline 5 & Professional Aspect & $0.787^{* *}$ \\
\cline { 2 - 3 } & Total stability & $0.813^{* *}$ \\
\hline \multirow{2}{*}{ ** significant at 0.01} & significant at 0.05
\end{tabular}

The previous table shows that the measure of emotional divorce for the working woman has a statistically high stability indicating a significance level (0.01).

B- Achievement Motivation Scale (prepared by Prof. Arafat Zaidan Khalil, 2000): The scale consists of (63) phrases divided into seven dimensions, namely: (obtaining success, "the need to excel," obtaining recognition, job satisfaction, ambition, perseverance, availability of knowledge about work, endurance and avoiding failure). All scale items were graded on a gradient (1-3), which is "yes, to some extent, no" and a high score indicates high levels of motivation to achieve. 
Finn scale: In the current study, the two researchers re-validated and validated as follows: Truthfulness: internal consistency as the tool was applied to a sample consisting of (20) items without the basic research sample and it has the same characteristics.

Table (4) illustrates Correlation coefficients between the degree of each dimension included in the scale and the total degree of the scale

\begin{tabular}{||l||l||}
\hline Dimensions & Correlation coefficient value \\
\hline \hline Get success "need to excel" & $0.834^{* *}$ \\
\hline \hline Get appreciation & $0.911^{* *}$ \\
\hline \hline Satisfaction with work & $0.816^{* *}$ \\
\hline \hline Ambition & $0.778^{* *}$ \\
\hline \hline Perseverance & $0.874^{* *}$ \\
\hline \hline Availability of knowledge about work & $0.791^{* *}$ \\
\hline \hline Stamina and avoid failure & $0.816^{* *}$ \\
\hline ** significant at 0.01 & $*$ significant at 0.05
\end{tabular}

It is clear from the table that all the correlation coefficients are statistically significant at a significant level $(0.01)$, which indicates the validity of the scale and its validity for use in what it was designed for.

Stability of the scale: The stability was calculated by several methods, represented by: the Cronbach's Alf method: where the reliability coefficient "Alpha" was (0.79), which is a high coefficient, and the method of split-half by using the Spearman Brown coefficient and its value (0.91). This indicates the validity of the scale is applicable.

Statistical methods used: After the process of collecting data and reviewing it in the field and in the office, the two researchers coded and coded the data and unpacked it using the statistical analysis program (SPSS V 25.0) and applied the following statistical methods:
1. Percentages and frequencies.
2. Arithmetic mean

Table (5) illustrates Levels of arithmetic means of the ternary scale

\begin{tabular}{||l|l||}
\hline \hline Low & If the mean value of the term or dimension ranges between 1: 1.66 \\
\hline \hline Medium & $\begin{array}{l}\text { If the mean value of the term or the dimension ranges between 1.67: } \\
2.33\end{array}$ \\
\hline \hline High & $\begin{array}{l}\text { If the mean value of the term or the dimension ranges between more } \\
\text { than } 2.34: 3\end{array}$ \\
\hline
\end{tabular}

3. The standard deviation.

4. Cronbach's Alpha test.

5.Pearson Correlation Coefficient.

6. Spearman Brown Coefficient.

7. Gamma correlation coefficient. 


\section{Sixth: the results of the study:}

Table (6) illustrates the level of emotional divorce of the working woman $(\mathrm{N}=100)$

\begin{tabular}{|c|c|c|c|c|}
\hline Dimensions & Mean & Standard Deviation & Ranking & Level \\
\hline The physical aspect & 2.50 & 0.344 & 4 & High \\
\hline The psychological aspect & 2.54 & 0.306 & 2 & High \\
\hline Social side & 2.49 & 0.306 & 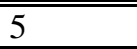 & High \\
\hline Affective side & 2.62 & 0.211 & $\overline{1} 1$ & High \\
\hline The professional side & 2.52 & 0.305 & 3 & High \\
\hline Total & 2.53 & 0.147 & $\overline{-1}$ & High \\
\hline
\end{tabular}

It is evident from the previous table that the level of emotional divorce among the working women, from the point of view of the study sample, is high, where the arithmetic mean is (2.53)., The indicators are according to the arrangement of the arithmetic mean: the emotional aspect came in the first order with an arithmetic mean (2.62). The psychological aspect came in the second order, with an arithmetic average (2.54). In the third place came the professional side with an arithmetic average (2.52), while the material side came in the fourth rank with an arithmetic average (2.50). In the fifth came the social side with an arithmetic average (2.49). The two researchers explain the high level of emotional divorce of the working woman due to the multiplicity of reasons and explain the increase in the marital gap between her and her husband and the increase in the emotional void between them, which was represented in the emotional, psychological, professional, material and social aspect.

The results of the current study also agree with the results of both Zeoli, et al. (2013) and Al-Hourani,\& Gharbawi, (2020) that emotional divorce is a major concern for wives and husbands, in which wives feel the dullness of marital relations, the discontinuity of emotions between them and the decline of feelings towards children. In addition to the deliberate neglect of the husband to the wife.

Table (7) illustrates the level of achievement motivation for working women

\begin{tabular}{||l||c||l||l||c||}
\hline \hline Dimensions & Mean & $\begin{array}{l}\text { Standard } \\
\text { Deviation }\end{array}$ & Ranking & Level \\
\hline \hline Get success "need to excel" & 1.61 & 0.378 & 4 & Low \\
\hline \hline Get appreciation & 1.62 & 0.321 & 3 & Low \\
\hline \hline Satisfaction with work & 1.54 & 0.306 & 7 & Low \\
\hline \hline Ambition & 1.64 & 0.364 & 2 & Low \\
\hline
\end{tabular}




\begin{tabular}{|lr||}
\hline Egyptian Journal of Social Work (EJSW) & http://ejsw.journals.ekb.eg \\
ISSN: 2356-9204 & Vol 12, Issue 1, June 2021 \\
\hline \hline
\end{tabular}

\begin{tabular}{|c|c|c|c|c|}
\hline Dimensions & Mean & $\begin{array}{l}\text { Standard } \\
\text { Deviation }\end{array}$ & Ranking & Level \\
\hline Perseverance & 1.56 & 0.322 & 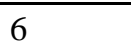 & Low \\
\hline $\begin{array}{l}\text { Availability of knowledge about } \\
\text { work }\end{array}$ & 1.65 & 0.375 & 1 & Low \\
\hline Stamina and avoid failure & 1.58 & 0.329 & 5 & Low \\
\hline Total & 1.60 & 0.174 & - & Low \\
\hline
\end{tabular}

It is evident from the previous table that the achievement motivation level of the working woman, from the point of view of the study sample, is low, as the arithmetic mean is (1.60). The indicators according to the arithmetic mean are ordered as follows. The availability of knowledge about work came in the first order with an arithmetic average (1.65). In the second order came Ambition with an arithmetic average (1.64). In the third place, came obtaining the estimate with an arithmetic average (1.62), while in the fourth order, it is obtaining success in the "need to excel" with an arithmetic average (1.61). In the fifth order, it is the ability to endurance and avoid failure with an arithmetic mean (1.58). In the sixth rank, perseverance came with an arithmetic mean (1.56), while in the seventh and final rank; it is for job satisfaction, with a mean of (1.54).

The two researchers explain the marked decrease in the level of achievement motivation for working women due to the multiplicity of factors that affect the achievement motivation of the working woman. This may be attributed to her personally, which is her personal and professional capabilities, and may be due to her family and family relations and the resulting many pressures, and may be due to socio-economic, social and political conditions, as well as the difficulties that contribute significantly to the decline in achievement motivation.

Consistent with the results of the study, Rasheed, et al., (2012) showed that $77 \%$ percent of the sample experienced emotional divorce at moderate-to-severe levels. In terms of employment, employed participants rated themselves to have lower emotional divorce than for unemployed participants, and couples with an age difference of more than 10 years demonstrated a higher level of emotional divorce than those 1 to 5 years apart in age. The results of the previous table are consistent with the study of both Saadet, (2012), Al-Ghamdi, (2000): Achievement motivation is linked to a number of other human factors such as achievement and practical 


\begin{tabular}{|lr||}
\hline Egyptian Journal of Social Work (EJSW) & http://ejsw.journals.ekb.eg \\
ISSN: 2356-9204 & Vol 12, Issue 1, June 2021 \\
\hline \hline
\end{tabular}

performance, and there is a strong correlation between the level of professional satisfaction and the level of achievement motivation among the counselors of vocational school guidance. The first hypothesis: There is an inverse correlation with statistical significance between emotional divorce and achievement motivation for the working woman "study sample".

Table (8) illustrates the relationship between emotional divorce and achievement motivation of working women "study sample"

\begin{tabular}{|c|c|c|c|c|c|c|}
\hline $\begin{array}{l}\frac{0}{0} \\
. \frac{\pi}{\pi} \\
>\end{array}$ & 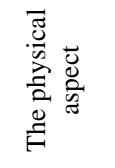 & 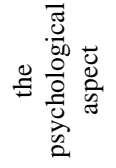 & 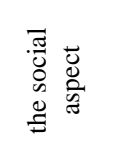 & 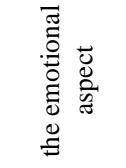 & 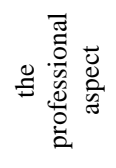 & 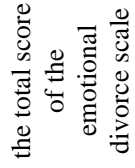 \\
\hline $\begin{array}{l}\text { Get success } \\
\text { "need to excel" }\end{array}$ & $-0.814 * *$ & $-0.286 * *$ & $-0.200 *$ & $-0.304 * *$ & $-0.300 * *$ & $-0.520 * *$ \\
\hline Get appreciation & -0.016 & $-0.247 *$ & $-0.748 * *$ & $-0.386 * *$ & $-0.459 * *$ & $-0.474 * *$ \\
\hline $\begin{array}{l}\text { Satisfaction } \\
\text { with work }\end{array}$ & -0.022 & $-0.211 *$ & $-0.205^{*}$ & $-0.753 * *$ & $-0.782 * *$ & $-0.418 * *$ \\
\hline Ambition & $-0.339 * *$ & $-0.305 * *$ & $-0.286 * *$ & $-0.359 * *$ & $-0.411 * *$ & $-0.260 * *$ \\
\hline Perseverance & -0.079 & $-0.735 * *$ & -0.036 & $-0.275^{* *}$ & $-0.386^{* *}$ & $-0.619 * *$ \\
\hline $\begin{array}{l}\text { Availability of } \\
\text { knowledge } \\
\text { about work }\end{array}$ & $-0.27 * *$ & -0.190 & $-0.286 * *$ & $-0.217 * *$ & $-0.318 * *$ & $-0.258 * *$ \\
\hline $\begin{array}{l}\text { Stamina and } \\
\text { avoid failure }\end{array}$ & -0.094 & $-0.334 * *$ & $-0.209 *$ & $-0.388 * *$ & $-0.436 * *$ & $-0.308 * *$ \\
\hline $\begin{array}{l}\text { Total } \\
\text { Achievement } \\
\text { Motivation }\end{array}$ & $-0.436 * *$ & $-0.442 * *$ & $-0.458 * *$ & $-0.652 * *$ & $-0.436 * *$ & $-0.711 * *$ \\
\hline
\end{tabular}

It is evident from the previous table that there is an inverse correlation relationship, which is statistically significant at the level (0.01) between the total measure of emotional divorce and the dimensions of achievement motivation of the working woman "study sample"., This confirms the validity of the first hypothesis that "there is an inverse correlation relationship with statistical significance between emotional divorce and the achievement motivation of the working woman is the "study sample".

The previous table shows that there is an inverse correlation relationship, which is statistically significant at a significant level (0.01) between the material aspect and most achievement motivation variables (obtaining success, "need to excel," ambition, availability of knowledge about work), and the overall degree of the measure of achievement motivation. This means that the greater the material side 
pressure as one of the factors leading to emotional disconnection, the lower these indicators are, and vice versa. The results of the table also showed the existence of an inverse correlation that is statistically significant at a significant level (0.01) between the psychological aspect, obtaining success, "need to excel", ambition, perseverance, endurance and avoiding failure, and the overall score of the achievement motivation scale, and at a significant level (0.05), with regard to obtaining appreciation, satisfaction with work., This means that the more psychological the aspect as one of the dimensions and causes of emotional divorce, the lower the achievement motivation in its dimensions, and vice versa, the lower psychological the aspect, the higher the achievement motivation in its dimensions for the working woman.

The results of the previous table also indicated the existence of an inverse correlation relationship that is statistically significant at a significant level (0.01) between the social aspect, the emotional aspect, the professional aspect and the rest of the achievement motivation variables for the working woman (the study sample) (obtaining success, the need to excel, obtaining the estimate, satisfaction with work, ambition, perseverance, availability of knowledge about work, endurance and avoidance of failure), and the overall degree of the achievement motivation scale, except for the absence of a correlation between the social aspect and the persistence variable on the achievement motivation scale. , This illustrates and indicates that with increasing pressure on the social, emotional and professional aspects related to emotional divorce decreases achievement motivation of working women and vice versa, which necessitates studying the emotional, social and professional aspects of working women in a way that contributes to increasing their motivation for achievement.

From the previous readings, this indicates that the greater the emotional divorce of the study sample of working women, the lower the achievement motivation for them, and vice versa; the lower the emotional divorce, the greater their achievement motivation. The researchers may attribute this to the large and varied marital pressures that they are exposed to, which affect them negatively, and that lead to the emergence of disorders and which is reflected in their professional lives. The results of the previous table are consistent with what the results of the study of both: Hassanein, (2016), Saadet, (2012) showed that achievement motivation is linked to a number of 
other human factors such as achievement and practical performance, the level of professional satisfaction, and the existence of an inverse relationship between the role struggle and the motivation for achievement of the working woman.

The second hypothesis: There is a statistically significant correlational relationship between some demographic variables (age, educational status of the working woman, the educational status of the husband, the employment status of the working woman, family income) and the emotional divorce of the working woman "study sample".

Table (9) illustrates the relationship between some demographic variables and emotional divorce for the working woman

\begin{tabular}{|c|c|c|c|}
\hline \multirow[b]{2}{*}{ Sr. } & \multirow[b]{2}{*}{ Demographic variables } & \multicolumn{2}{|c|}{ Emotional divorce } \\
\hline & & $\begin{array}{l}\text { The parameter } \\
\text { used }\end{array}$ & $\begin{array}{l}\text { Its value and } \\
\text { significance }\end{array}$ \\
\hline 1 & Age & Pearson & $0.295 * *$ \\
\hline 2 & The educational status of working women & Gamma & 0.083 \\
\hline 3 & The husband's educational status & Gamma & 0.011 \\
\hline 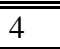 & Employment status of working women & Gamma & 0.076 \\
\hline 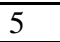 & Family income per month & Pearson & $0.520 * *$ \\
\hline
\end{tabular}

** significant at $0.01 \quad$ * significant at 0.05

It is clear from the previous table that there is a statistically significant relationship between one of the demographic variables and the emotional divorce of the working woman "study sample", i.e. (age, family income). This means that emotional divorce differs according to some demographic variables of the working woman "study sample" and the rest of the other variables do not differ according to its differences, which makes us accept the second hypothesis of the study. Also, there is a statistically significant correlation between some demographic variables (age, educational status of the working woman, the educational status of the husband, the working status of the working woman, the family income) and emotional divorce of the working woman".

The results of the previous table also indicate the existence of an inverse correlation between the age variable as one of the demographic variables and the emotional divorce of the working woman (study sample), which indicates that the younger the age of husbands and wives, the greater the possibility of increasing the emotional dimension and leading to an increase in emotional divorce between them as a result of inexperience. and the lack of emotional 
and marital maturity. This weakens their motivation in overcoming life's difficulties. On the other hand, the greater the age variable among husbands and working wives (study sample), the less likely emotional divorce is due to the increase in marital experience and clarity of emotional maturity in both of them, which makes them more able to overcome family problems and face the difficulties of life.

The results of the previous table also indicate the existence of an inverse correlation between the income variable as one of the demographic variables and the emotional divorce, which indicates that the family income as one of the demographic variables has a significant impact on the existence of emotional divorce among the working woman in the study sample, as the lower incomes of the woman's family, the more it leads to an increase in the likelihood of an emotional divorce between the spouses, which imposes on them many problems as a result of the failure to meet the basic needs and requirements of the family. This is reflected negatively on the family relations between the spouses.

The third hypothesis: There is a statistically significant correlation between some demographic variables (age, the educational status of the working woman, the educational status of the husband, the working status of the working woman, the family income) and the achievement motivation of the working woman "study sample".

Table (10) illustrates the relationship between some demographic variables and achievement motivation for working women

\begin{tabular}{|c|c|c|c|}
\hline \multirow[t]{2}{*}{ Sr. } & \multirow{2}{*}{ Demographic variables } & \multicolumn{2}{|c|}{ Achievement motivation } \\
\hline & & $\begin{array}{l}\text { The parameter } \\
\text { used }\end{array}$ & $\begin{array}{l}\text { Its value and } \\
\text { significance }\end{array}$ \\
\hline 1 & Age & Pearson & $0.339 * *$ \\
\hline 2 & $\begin{array}{l}\begin{array}{l}\text { The educational status } \\
\text { working women }\end{array} \\
\text { of }\end{array}$ & Gamma & $0.250^{*}$ \\
\hline 3 & The husband's educational status & Gamma & 0.037 \\
\hline 4 & $\begin{array}{l}\text { Employment status of working } \\
\text { women }\end{array}$ & Gamma & $0.305^{* *}$ \\
\hline 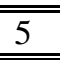 & Family income per month & Pearson & $0.458^{* *}$ \\
\hline
\end{tabular}

It is clear from the previous table that there is a statistically significant relationship between one of the demographic variables 
and achievement motivation for the working woman, the "study sample", which is a variable (age, educational status of the working woman, the working woman's employment status, family income per month), which indicates that achievement motivation varies according to some demographic variables of the working woman "the study sample" and the rest of the other variables of the achievement motivation do not differ accordingly. This makes us accept the second hypothesis of the study, which is the third hypothesis: There is a statistically significant correlation between some demographic variables (age, educational status of working women, employment status of women Worker, family income) and achievement motivation of the working woman "study sample."

The results of the current study agree with the results of the study of both: Abdel-Aal, (2011), Muhammad, (2004), that there are statistically significant differences between women with higher education and women with medium education in professional and family pressures between professional and family pressures and achievement motivation. There are also statistically significant differences between some achievement motivation items for female heads of families according to the study variables (type of dependency- place of residence- duration of dependency- educational level of the breadwinner woman- number of children- family income) at the level of significance (0.05), (0.01). There are also statistically significant differences between female heads of households in both (rural and urban areas) and between some dimensions of achievement motivation at the level of significance (0.01). Finally, there is a correlation between the breadwinner woman's management of family crises and her motivation for achievement at a significant level (0.01). Also, there are no differences between the types of crises facing a breadwinner woman and the number of children.

\section{Discussion}

The study reached the fulfillment of the study hypotheses and The results illustrates the relationship between emotional divorce and achievement motivation of working women "study sample" agree with what was reported by the results of both: Magd, et al., (2019), Zeoli, et al., (2013), the existence of a correlation between the variables of emotional divorce and the indolence in marital relations and the discontinuity of emotions between them. There is also a positive statistically significant correlation between emotional divorce and the satisfaction of emotional and social needs. 
The results of the current study are also consistent with the study of both: Abdel-Latif, (2020), Toga, et al., (2014) There is a statistically significant positive relationship between work and family conflict and job satisfaction that has a large percentage of professional pressures, and the existence of differences in the degree of emotional divorce. Linked to gender are number of years of marriage, level of education and income level per month for the study sample.

The results of the study illustrates the relationship between some demographic variables and emotional divorce for the working woman are different from the results of Rasheed, et al., (2021) which indicated that couples with an age difference of more than 10 years demonstrated a higher level of emotional divorce than those 1 to 5 years apart in age.

The results of the study are also consistent with the study Abdel-Latif, (2020) in the presence of differences in the degree of emotional divorce (age, number of years of marriage and the level of monthly income), but they differed from the results of the current study, which proved that there is no relationship between emotional divorce and some demographic variables such as type and level Education between spouses.

The results of the current study are also in line with what was reported by the results of the study Hassanein, (2016) regarding the existence of a statistically significant inverse relationship between the role struggle and the motivation for achievement of the working woman. Also, the results of the study showed that there is a relationship between satisfaction with work inside and outside the home and higher motivation for women to achieve.

The results of the current study also clarify through the theoretical framework according to the role theory in the current research, which relates to the fact that women in the Egyptian society do not play one role, but they play more than one role. This is because they play a set of roles within the family as they are the mother of a child, wife, an employee and a colleague of her colleagues at work and subordinate to her boss, who corresponds to the total roles that women play in a way that reduces her motivation for achievement. Thus, there is a conflict of roles between the spouses as a result of psychological and social pressures, which weakens their relationship. 


\section{References:}

Abdel-Aal, Amira Hassan (2011). Management of breadwinner

women in family crises and their relationship

to achievement motivation, unpublished $\mathrm{PhD}$ thesis, Faculty of Education, Ain Shams University.

Abdel- Latif, M. Sabah (2020). The deficiency of emotional organization as a precursor to emotional separation of a sample of male and female teachers, an unpublished master's thesis, Faculty of Education, Fayoum University.

Afrasiabi, Fatemeh. \& Jafarizadeh, R. Mohammad. (2015). Study of the Relationship between Personal Factors and Emotional Divorce. Mediterranean Journal of Social Sciences, 6 (6).

Al-Ghamdi, Abdullah bin Muhammed (2000). Differences in self-concept and achievement motivation among a sample of underprivileged and unprivileged adolescents in Jeddah Governorate, MA Thesis, Jeddah: College of Education, Umm Al-Qura University.

Al-Haqbani, Saad (2013). Family Counseling Handbook (the problem of emotional divorce and how the family guide deals with it), Saudi Arabia. King Fahd National Library.

Al-Siddiqi, Salwa Othman, and Ramadan, Al-Sayed (2004). The method of working with individuals: theoretical approaches and applied processes, Alexandria: University Knowledge House.

Al-Hourani, A. Muhammad.\& Gharbawi, Fatima (2020). The emotional divorce between spouses from the perspective of the wife in the Emirati family, Application of Hochschlid's Theory of Affective Action. the Journal of the College of Arts, University of Sharjah,133.

Barzoki, H. Meysam., Tavakoll, Mohhamad. \& Burrage, Hilary. (2015). Rational-Emotional 'Divorce' in Iran Findings of Qualitative Research on Women with Marital Dissatisfaction. Applied Research Quality Life, 10:107-122.

Chang, E. Young.\& Kim, Hee-Jin.(2016). The Relationship between Job-Role Quality and Parenting Behaviors among Employed Mothers in Korea. Journal of Comparative Family Studies, 47(4): 527548.

Hamza, I. Ahmed., El-Sayed. A.Hanan.\& Mansour, M. Amr (2016). Women Contemporary Issues and Problems. Riyadh: Dar AlZahraa.

Hashemi, Ladan. \& Homayuni, Halleh. (2017). Emotional Divorce: Child's Well-Being. Journal of Divorce \& Remarriage, 58 (8): 631-644.

Hassanein, Lily Kamel Ahmad (2016). The conflict of roles for working women and its relationship to their achievement motivation within the framework of the theory of the social role in serving the individual. an unpublished master's thesis, Faculty of Social Work, Helwan University.

Henderson, J. Z.A., Bartholomew, K.\& Dutton, G.D. (1997). He Loves Me; He Loves Me Not: Attachment and Separation Resolution of Abused Women. Journal of Family Violence, 12 (2):169-191. 
Khoury, Nesim's (2008). Marriage, a psycho-social comparison.

Beirut: Dar Al-Manhal Al-Lebanese for publication and distribution.

Magd, A. Samir., Rakhawya, Moustafa., Mamdouha, Rania.\&

Shaheen, Somaya.(2019). Impulsivity, suicidality, and emotional dysregulation in women having borderline personality disorder with and without substance dependence. Egyptian of Psychiatry, 40 (2): 5963.

Mayo, M. James.\& Johnson, J. Bonnie .(2011). A Role Dynamics

Theory of Planning. Journal of Architectural and Planning Research, 28 (2): 91-103.

Muhammad, Madiha Saad Zaghloul (2004). Professional and family pressures and their relationship to the motivation for achievement of working women. Master Thesis, Department of Psychology, Faculty of Arts, Minia University.

Rasheed, Abeer., Amr, Ahmad .\& Fahad, Nora. (2021).

Investigating the Relationship between Emotional Divorce, Marital Expectations, and Self-Efficacy among Wives in Saudi Arabia. Journal of Divorce \& Remarriage, 62 (1): 19-40.

Saadet, Bouazaz (2012). Professional satisfaction and its relationship to achievement motivation for school and vocational guidance and counseling consultants, MA Thesis, Algeria: Institute of Human and Social Sciences, Department of Psychology.

Stanton, Mark. \& Lee, Michael. (2017). Social Role Theory in Couple and Family Therapy. In Encyclopedia of Couple and Family Therapy. Springer International Publishing.

Taha, F. Abdel Qader., et al. (2003). Encyclopedia of Psychology and Psychoanalysis. Cairo: Dar Gharib for Printing and Publishing.

Tempelaar, T. Dirk., Loeff, S.V. Sybrand., Gijselaers, H.Wim.\& Nijhuis, F.H. Jan. (2011). On Subject Variations in Achievement Motivations: A Study in Business Subjects. Research in Higher Education , 52(4): 395-419.

The Central Agency for Public Mobilization and Statistics.

(2019). Analytical Report of the Annual Bulletin of Marriage and Divorce Statistics.

Toga, Raymond., Binqela, Thembisa.\& Mjoli, Q. Themba.(2014).

Job Satisfaction as a Moderator of the Relationship between WorkFamily Conflict and Stress among Female Civil Service Managers. Mediterranean Journal of Social Sciences, 5 (2).

Uzoigwe, G. Anthonia., Low, Y. Wah.\& Noor, N. Siti .(2016).

Predictors of Work-Family Role Conflict and Its Impact on Professional Women in Medicine, Engineering, and Information Technology in Nigeria. Asia Pacific Journal of Public Health, 28 (7): 629-637.

Voydanoff, Patricia. (1988). Work Role Characteristics, Family Structure Demands, and Work/Family Conflict. Journal of Marriage and Family, 50 (3): 749-761. 
Zeoli, M. April., Rivera, A. Echo., Sullivan, M. Cris.\& Kubiak,

Sheryl.(2013). Post-Separation Abuse of Women and their Children: Boundary-Setting and Family Court Utilization among Victimized Mothers. Journal of Family Violence, 28(6): 547-560. 